\title{
Optical, Structural, and Electrical Properties of Aromatic Triphenylamine-Based Poly(azomethine)s in Thin Layers
}

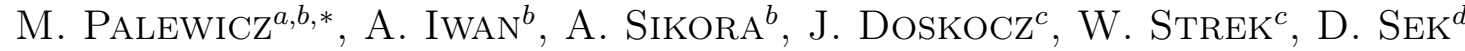 \\ AND B. MAZUREK ${ }^{b}$ \\ ${ }^{a}$ Institute of Electrical Engineering Fundamentals, Wrocław University of Technology \\ Wybrzeże Wyspiańskiego 27, 50-370 Wrocław, Poland \\ ${ }^{b}$ Electrotechnical Institute Division of Electrotechnology and Materials Science \\ M. Skłodowskiej-Curie 55/61, 50-369 Wrocław, Poland \\ ${ }^{c}$ Institute of Low Temperature and Structure Research, Polish Academy of Sciences \\ Okólna 2, 50-422 Wrocław, Poland \\ ${ }^{d}$ Centre of Polymer and Carbon Materials, Polish Academy of Sciences \\ M. Skłodowskiej-Curie 34, 41-819 Zabrze, Poland
}

\begin{abstract}
Spectroscopic and photophysical properties of the poly(azomethine)s with triphenylamine moieties were investigated by UV-vis, X-ray diffraction and atomic force microscopy methods. Current-voltage measurements were performed on ITO/polymer/Alq $/ \mathrm{Al}$, ITO/PEDOT/polymer:MWCNT/Al and ITO/polymer:MWCNT/Al devices. Multiwall carbon nanotubes were blended with polymer in the ratio 1:1. The lowest optical band gap value at $2.33 \mathrm{eV}$ was detected. Moreover, an absorption coefficient $\alpha$ was calculated from transmission and reflectivity measurements. In this paper, we presented photophysical and structural properties of the poly(azomethine)s in solid state of great interest for the emerging field of molecular electronics and for their uses as active layers in (opto)electronic devices such as solar cells.
\end{abstract}

PACS: 77.84.Jd, 73.61.Ph, 78.66.Qn

\section{Introduction}

Pi-conjugated polymers have been subject of extensive research interest in the past three decades because they exhibit interesting optical, electronic and electrochemical properties unobtainable for conventional polymers [1-3]. In particular they can be used as components of so-called "plastic electronics" in such devices as light-emitting diodes (LED)s, polymeric solar cells, field-effect transistors (FET)s or lasers. The most important advantage of the use of polymers as active components of electronic devices is the possibility of a precise tuning of their band gap $\left(E_{\mathrm{G}}\right)$ and by consequence optical and electronic properties via chain engineering. Aromatic poly(azomethine)s i.e. polymers containing $\mathrm{CH}=\mathrm{N}-$ groups in the main chain, called also poly (imine)s, being isoelectronic with the corresponding poly ( $p$-phenylene vinylene) (PPVs), also exhibit interesting electronic, luminescent and non-linear optical properties [4]. Among the huge class of poly(azomethine)s, polymers with triphenylamine units are very attractive as hole transport materials for opto(electrical) applications [5-12]. For example, Niu et al. [5, 6] studied poly(azomethine)s obtained from 4,4'-diaminotriphenylamine and terephthalic aldehyde or glyoxal.

* corresponding author; e-mail: m.palewicz@iel.wroc.pl
Current-voltage measurements of a device having construction ITO $/ \mathrm{PAZ} / \mathrm{Alq}_{3} / \mathrm{Al}$ showed that green electroluminescence was clearly observed at a voltage about 5.4 V. Sek et al. [7-10] investigated photoluminescence properties of a series of poly(azomethine)s synthesized in polycondensation reaction of $4,4^{\prime}$ -diformyltriphenylamine and various aromatic diamines. Current-voltage characteristics of devices having the structure ITO $/ \mathrm{PAZ} / \mathrm{Alq}_{3} / \mathrm{Al}$ revealed that the turn-on voltage was observed at about $6 \mathrm{~V}$ in room temperature [9]. Hindson et al. [12] presented photovoltaic properties of triphenylamine-based polyazomethines obtained from 2,5-thiophenedicarboxaldehyde ( $\mathrm{Th}$ ), terephthalaldehyde (Ta) or 1,3-isophthalaldehyde (Iso) and 4,4'-diaminotriphenylamine (TPA). A photovoltaic device based on a TPA-Th/PCBM blend (1:3) (PCBM: [6,6]-phenyl-C61-butyric acid methyl ester) under simulated sunlight exhibited a power conversion efficiency at about $0.12 \%$, while for the TPA-Ta/PCBM blend (1:3) and TPA-Iso/PCBM blend (1:3) a power conversion efficiency were found at about $0.19,0.02 \%$, respectively.

On the other hand, carbon nanotubes are very interesting as nanocomposites, which have many interesting properties in different application fields, e.g. nanoelectronic devices, automotive, aeronautic and aerospace industries [13-18]. It is obvious that a large variety of thermophysical properties depends on the structure and diameter of nanotubes. Carbon nanotubes 


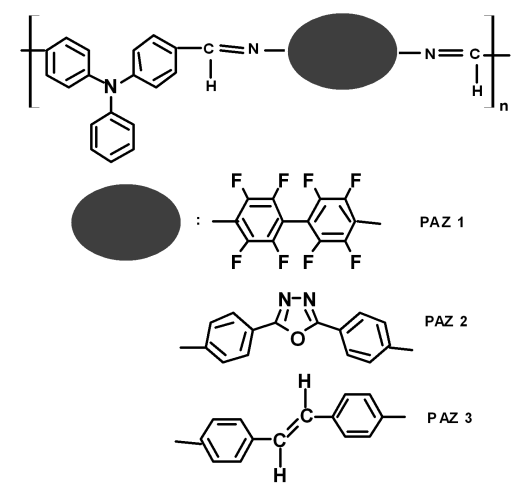

Fig. 1. Chemical structure of the investigated polymers.

exhibited high tensile strength and Young's modulus and are interesting as components in polymer composition $[14,19]$. We found only one paper [19] where poly(azomethine)-carbon nanotube composite was investigated by different types of microscopy such as atomic force microscopy (AFM), polarized optical microscopy (POM) and scanning electron microscopy (SEM). In [19] poly (azometine)-MWCNT (multiwall carbon nanotubes) compositions were prepared by a step polymerization in presence of MWCNT. Inspired by the above described findings we have undertaken a detailed study of the structural and opto(electrical) properties in a series of poly(azomethine)s (abbreviated hereinafter as PAZ) thin films prepared via spin-coating technique. Such following methods as UV-vis, PL, current-voltage $(I-V)$, $\mathrm{X}$-ray diffraction and AFM experiments were used. Surprisingly literature data concerning optical properties of PAZ thin layers are rather scarce [20-25], yet PAZ seem to be excellent candidates for new polymeric materials with quite low value of $E_{\mathrm{G}}$ because in addition to a rather facile tuning of their spectroscopic properties they should exhibit better thermal stability as compared to other polymers with (opto)electronic properties.

In this paper structural and optical properties of poly(azomethine) with ethylene linkage (PAZ3) were compared with the properties of PAZ1 and PAZ2. With this background it is important to know the influence of structural parameters on the specific properties of the polymers. The polymers are shown in Fig. 1.

\section{Experimental}

\subsection{Measurements techniques}

The optical properties of thin polymer layers were measured by two-beam spectrophotometer Cary 5000. Photoluminescence of polymer thin layers was detected by Spectrofluorimeter Co. Dongwoo Optron (DM711 and DM152i). The surface morphology of the polymers prepared via spin-coating technique on the quartz substrates were performed in air using an Atomic Force Microscope Innova instrument from Veeco Co. in the tapping mode with typical phosphorus doped silicon cantilever: $40 \mathrm{~N} / \mathrm{m}$ and $<10 \mathrm{~nm}$ of the tip radius. X-ray diffraction curves were performed using thin film samples on a Pulveraceous diffractometer Dron-2. Co radiation filtrated by Fe was applied. Current-voltage $(I-V)$ characteristics of samples were obtained using Keithley electrometer 6517A at room temperature.

\subsection{Device fabrication}

Current-voltage measurements were performed on $\quad \mathrm{ITO} /$ polymer $/ \mathrm{Alq}_{3} / \mathrm{Al}, \quad \mathrm{ITO} / \mathrm{PEDOT} / \mathrm{poly}$ mer:MWCNT/Al and ITO/polymer:MWCNT/Al devices. Indium tin oxide (ITO) and quartz were situated in ultrasonic washer with deionised water for 10 min. After that substrates were cleaned in solution of deionised water, 2-propanol and toluene, and washed in deionised water and acetone. On ITO or ITO/PEDOT substrates polymers were spread using spin-coating method with angular speed 880 turn per min by $10 \mathrm{~s}$. $\mathrm{Alq}_{3}$ (tris(8-hydroxyquinolinato)aluminium) layer was prepared on the polymer film surface by vacuum deposition at a pressure of $5 \times 10^{-4}$ Torr. Polymer:MWCNT thin films were overlapped using spin-coating equipment. Mixture of polymers and MWCNTs were spread from chloroform solution, while PEDOT (poly(3,4-ethylenedioxythiophene)) were spin-coated from water solution. All devices were annealed at $50^{\circ} \mathrm{C}$ per $12 \mathrm{~h}$ to dispose of solvent from thin layers. Then $\mathrm{Al}$ electrode was prepared on the polymer or polymer:MWCNT film surface by thermal evaporation at a pressure of $5 \times 10^{-4}$ Torr. The thickness of polymer and polymer:MWCNT was about $200 \mathrm{~nm}$. For PEDOT and $\mathrm{Alq}_{3}$ thickness of layers were about $150 \mathrm{~nm}$. The area of the measuring aluminum electrode was about $50 \mathrm{~mm}^{2}$

\section{Results and discussion}

\section{1. $U V$-vis measurement}

In this paper photophysical and structural properties of the poly(azomethine)s thin layers were investigated. Polymers were prepared in $\mathrm{CHCl}_{3}$ and spin-coated on the quartz slides for UV-vis measurements. All polymers exhibit one clear absorption peak in the range 408-421 nm, responsible for the transition in imine groups and depended on the kind of diamine structure (Table I).

Optical properties such as maximum of absorbance and optical band gap of measured samples are given in Table I. If a structure of the diamine is taken into consideration it can be seen that vinylene unit in PAZ3 influence on the $6 \mathrm{~nm}$ blue (hypsochromic) shift in UV-vis absorption spectrum in comparison with the PAZ1 and $5 \mathrm{~nm}$ red (bathochromic) shift in comparison with the PAZ2 (Table I). This behavior confirmed the influence of diamine structure on the value of absorption band. In our case 4,4'-diaminooctafluorobiphenyl was used as an acceptor in the poly(azomethine) PAZ1, while 2,5-bis(4-aminophenyl)-1,3,5-oxadiazole was applied as a donor in PAZ2. Additionally, dependence on the substrate second absorption band existed mainly as a hump was observed (Fig. 2a). 
TABLE I

$\mathrm{UV}$-vis and photoluminescence (PL) properties of poly(azomethine)s thin layers.

\begin{tabular}{c|c|c|c|c}
\hline \hline \multirow{2}{*}{ Code } & \multicolumn{2}{|c|}{$\begin{array}{c}\text { absorption maximum } \\
{[\mathrm{nm}] /[\mathrm{eV}]}\end{array}$} & $\begin{array}{c}\text { Energy band } \\
\text { gap }[\mathrm{eV}]\end{array}$ & $\begin{array}{c}\text { Photoluminescence } \\
{[\mathrm{nm}] /[\mathrm{eV}]}\end{array}$ \\
\cline { 2 - 5 } & \multicolumn{3}{|c}{ on quartz } \\
\cline { 2 - 5 } & $\lambda_{1}$ & $\lambda_{2}$ & $E_{\mathrm{G}}$ & $\lambda_{\mathrm{emis}}$ \\
\hline PAZ1 & $419 / 2.96$ & $262 / 4.73$ & 2.35 & $479 / 2.59$ \\
PAZ2 & $408 / 3.04$ & $334 / 3.71$ & 2.37 & $465 / 2.67,559 \mathrm{sh}$ \\
PAZ3 & $415 / 2.99$ & $244 / 5.08$ & 2.33 & $497 / 2.49$ \\
\hline
\end{tabular}

sh - shoulder

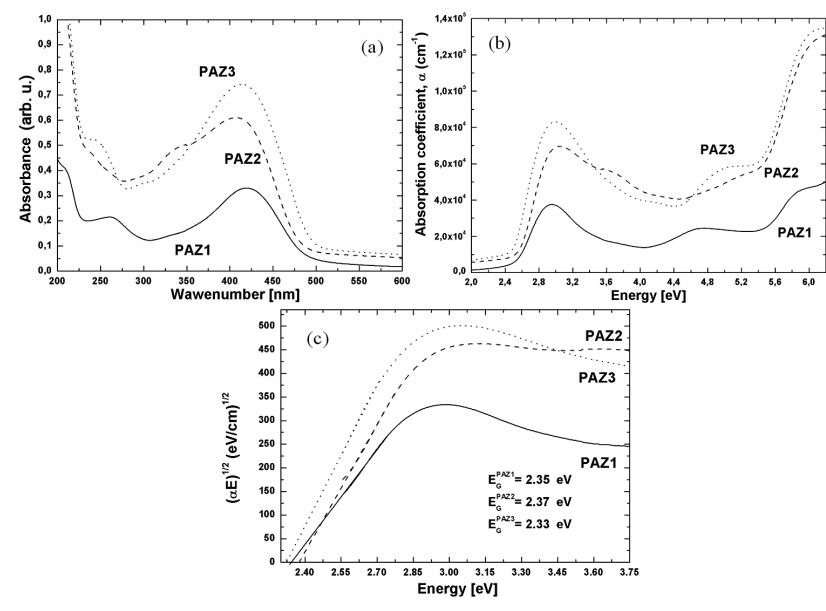

Fig. 2. (a) Room temperature solid state UV-vis absorption spectra of poly(azomethine), (b) absorption coefficient of PAZs and (c) linear approximation of absorption edges of the poly(azomethine)s.

UV-vis spectra of the poly(azomethine)s on the quartz substrate exhibited one main absorption band and hump. Similar behavior of the UV-vis absorption properties of another poly (azomethine)s in thin films was described in [24-26]. An absorption coefficient $\alpha$ was calculated according to the equation $\alpha=\frac{1}{d} \ln \left(\frac{(1-R)^{2}}{T}\right)$ given in Ref. $[27,28]$, where $d$ is film thickness and was about $200 \mathrm{~nm}$ for all polymers, $T$ - transmission and $R$ - reflectivity.

Absorption coefficient plots of the PAZ1-PAZ3 thin layers are presented in Fig. 2b. The optical band gap $\left(E_{\mathrm{G}}\right)$ of the poly(azomethine)s was observed in the range 2.33-2.44 eV and depended on the polymer structure.

For amorphous semiconductive materials it is possible to calculate the optical energy band gap $E_{\mathrm{G}}$ from the equation $\alpha E=A\left(E-E_{\mathrm{G}}\right)^{r}$, where $\alpha$ is absorption coefficient, $A$ is parameter independent of photon energy, $E, E_{\mathrm{G}}$ represent photon and band gap energy, respectively. Index $r$ is related with different types of transition.

In our case index $r$ is connected with indirect band to band transition and has the value $r=2$. It means that in investigated polymers excitation of electrons was proceeded by absorbing a photon and interaction with phonon. Probably that phenomenon is caused by the presence in the structure of the poly(azomethine) triphenylamine unit. In our case such approach leads to equation $(\alpha E)^{1 / 2}=f(E)$ and that was connected with additional $\pi$ bonds coming from triphenylamine unit in the polymer structure. Linear approximation of absorption edge of the poly(azomethine)s thin layers is shown in Fig. 2c.

\subsection{Photoluminescence measurements}

Tuning the chemical structure and band gap of conjugated polymers and designing LEDs emitting selected colors remains a challenging issue. In our work photoluminescence (PL) spectra of the investigated poly(azomethine)s were measured in solid state as a thin layer coated on quartz substrate by spin-coating technique. PL of the poly(azomethine)s was observed in the range of 465-497 $\mathrm{nm}$, and the emission band was red shifted in the following order: PAZ2 < PAZ1 < PAZ3. All investigated poly(imine)s emitted blue light (see Table I). PAZ3 was $18 \mathrm{~nm}$ bathochromically shifted in comparison with PAZ1 and $32 \mathrm{~nm}$ red shifted in comparison to PAZ2 (Table I). PL spectra of the poly(azomethine)s in thin film are presented in Fig. 3.

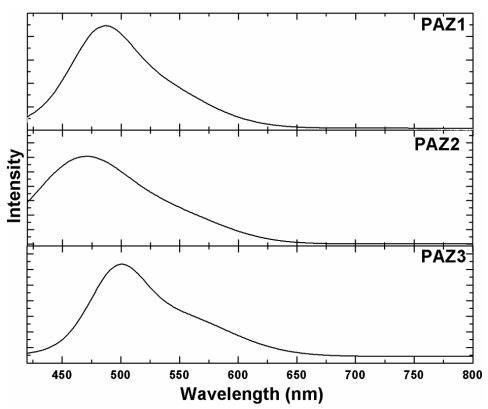

Fig. 3. Room temperature PL spectra and matching (red line) of PAZs films. 


\subsection{Structural characteristics}

The wide-angle X-ray diffraction patterns of all polymers over the $2 \theta$ range of $10-60 \mathrm{deg}$ are shown in Fig. 4.

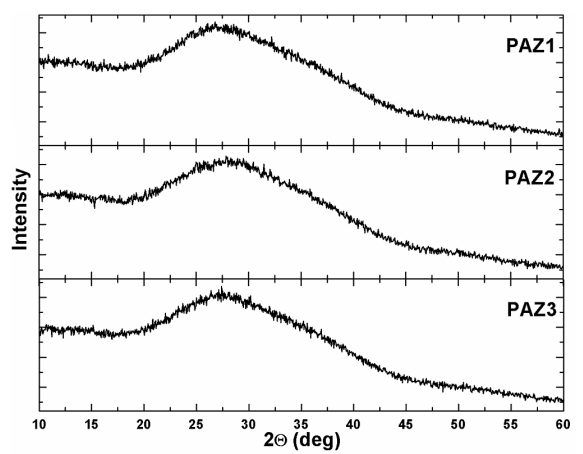

Fig. 4. X-ray diffraction patterns of poly(azomethine)s films.
One broad diffraction peak of diffusion type centered at about $27^{\circ}(2 \theta)$ was observed for all polymers. X-ray diffraction patterns allowed to conclude that investigated material had an amorphous structure which was expected and also discussed for another type of poly(azomethine)s $[5,28]$.

AFM experiment was used to investigate the influences of the polymer structure on the surface morphology of the materials. Figure 5 shows AFM images obtained for all poly(azomethine)s thin layers.

When the topography of the surface was measured, one can extract certain data describing its properties. Most popular parameters are roughness factors $\left(R_{\mathrm{a}}, R_{\mathrm{ms}}\right)$. It is useful however to use in addition also a skew (the unbalance of height distribution maximum) and kurtosis (the peak's width on height distribution). The surface area ratio as the relation of the surface's area and the scan field was calculated as well. Mentioned values for investigated surfaces are presented in Table II.

The surface parameters of poly(azomethine)s.

TABLE II

\begin{tabular}{c|c|c|c|c|c}
\hline \hline \multirow{2}{*}{ Code } & \multicolumn{5}{|c}{ Surface statistics* } \\
\cline { 2 - 6 } & $R_{\mathrm{a}}[\mathrm{nm}]$ & $R_{\mathrm{ms}}[\mathrm{nm}]$ & Skew & Kurtosis & $\begin{array}{c}\text { Surface area } \\
\text { ratio }\end{array}$ \\
\hline PAZ1 & 1.13 & 1.85 & -3.25 & 16.7 & 1.0056 \\
PAZ2 & 0.43 & 0.55 & -0.359 & 1.1 & 1.0019 \\
PAZ3 & 0.79 & 1.08 & 0.752 & 2.92 & 1.0040 \\
\hline
\end{tabular}

* values calculated for scanning field $2 \mu \mathrm{m} \times 2 \mu \mathrm{m}\left(4 \mu \mathrm{m}^{2}\right.$ scan area $)$

The thin films of the PAZs on the quartz presented a homogeneous surface. PAZ1 and PAZ3 samples revealed homogeneously distributed holes of about $51 \mathrm{~nm}$ and $10 \mathrm{~nm}$, respectively. It should be mentioned that in PAZ3, due to specific crater-like structures shapes, their size is significantly bigger than holes, and is about $90 \mathrm{~nm}$. Characteristic granulation was typical for the polymers thin layers and also aggregates were clearly visible in Fig. 5. It was also possible to calculate dimension of granulated polymers on substratum from images presented in Fig. 5d-f. Magnitudes of nodule for PAZ2 and PAZ3 were about $100 \mathrm{~nm}$.

\subsection{Current-voltage measurement}

Devices having the following architecture: ITO/ polymer/Alq $/ \mathrm{Al}$, ITO/polymer:MWCNT/Al, ITO/ $\mathrm{PEDOT} /$ polymer:MWCNT/Al, were constructed. In this work, triphenylamine was used as the electron-donating group, due to its excellent solubility, good stability, high photoluminescence and importance as a hole transport molecule in devices, while $4,4^{\prime}$ -diaminooctafluorobiphenyl (in PAZ1) was employed as the electronacceptor (A) or 2,5-bis(4-aminophenyl)-1,3,5-oxadiazole (in PAZ2) and 4, $4^{\prime}$-diaminostilbene (in
PAZ3) as the electron-donating group (D). PEDOT (poly(3,4-ethylenedioxythiophene) was used as a separate layer in device construction to improve electrical properties of the devices. $\mathrm{Alq}_{3}$ (tris $(8$ hydroxyquinolinato)aluminium) plays the role of an electron injection transport and emitting layer. First, currentvoltage $(I-V)$ measurement of PAZ1 performed on ITO/ polymer $/ \mathrm{Alq}_{3} / \mathrm{Al}$ device was investigated. The turn-on voltage of the device ITO/PAZ1/ $\mathrm{Alq}_{3} / \mathrm{Al}$ was observed at about $6.0 \mathrm{~V}$ in room temperature. Current voltage curve of ITO $/ \mathrm{PAZ1} / \mathrm{Alq}_{3} / \mathrm{Al}$ device is shown in Fig. 6a.

Differences were found along with change of the device structure. It can be seen that for the device ITO/PAZ1:MWCNT/Al the turn-on voltage of this device was observed at about $4.0 \mathrm{~V}$ in room temperature, while for the devices ITO/PAZ2:MWCNT/Al and ITO/PAZ3:MWCNT/Al the turn-on voltage was observed at about $2.0 \mathrm{~V}$ in room temperature. Current-voltage curves of ITO/PAZ1:MWCNT/Al, ITO/PAZ2:MWCNT/Al and ITO/PAZ3:MWCNT/Al are shown in Fig. 6a,c,d.

Additionally, we investigated also influence of PEDOT layer for current-voltage characteristic of such device 


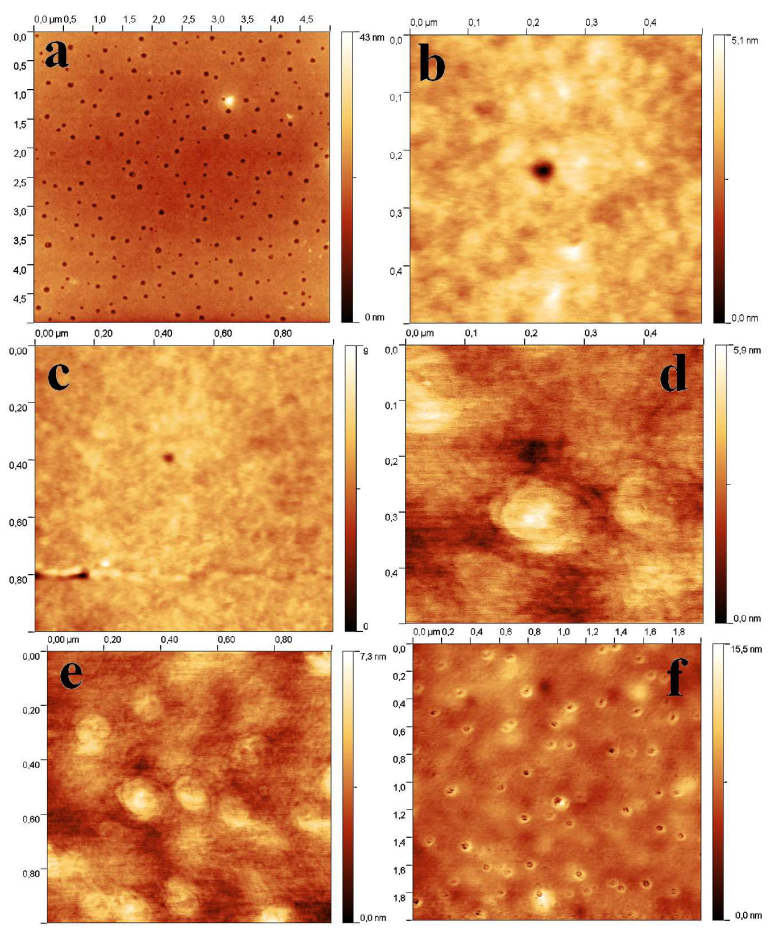

Fig. 5. AFM images of (a) PAZ1, (b,c) PAZ2 and (d,e,f) PAZ3 films.

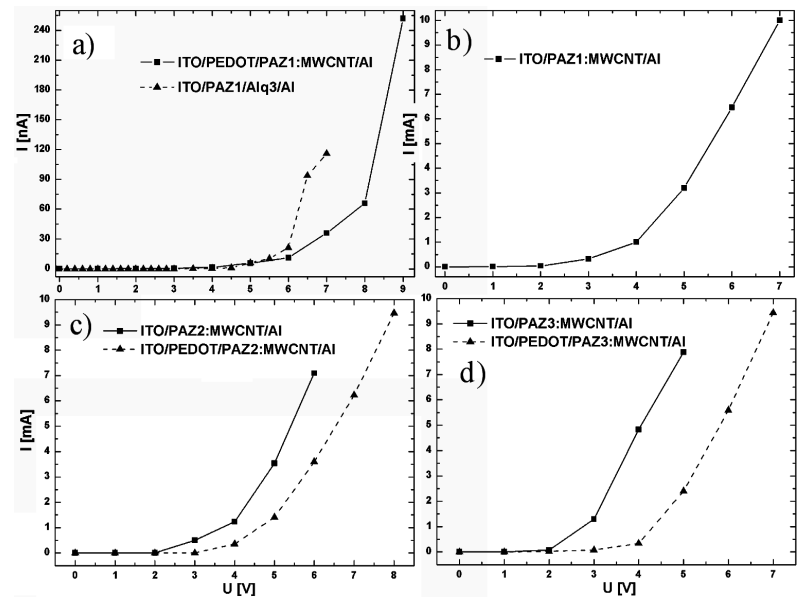

Fig. 6. Current-voltage characteristics of devices: (a) ITO $/ \mathrm{PAZ1} / \mathrm{Alq}_{3} / \mathrm{Al}, \quad \mathrm{ITO} / \mathrm{PEDOT} /$ $\mathrm{PAZ1}: \mathrm{MWCNT} / \mathrm{Al}, \quad$ (b) ITO/PAZ1:MWCNT/Al,

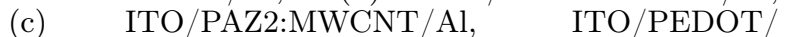
PAZ2:MWCNT/Al, and (d) ITO/PAZ3:MWCNT/Al, ITO/PEDOT/PAZ3:MWCNT/Al.

as ITO/PEDOT/polymer:MWCNT/Al. For example, for the device ITO/PEDOT/PAZ1:MWCNT/Al the turn-on voltage was observed at about $6.0 \mathrm{~V}$ in room temperature, while for the devices ITO/ PEDOT/PAZ2:MWCNT/Al and ITO/PEDOT/ PAZ3:MWCNT/Al the turn-on voltage was observed at about $3.0 \mathrm{~V}$ and $4.0 \mathrm{~V}$, respectively.
This behavior confirmed the influence of the polymer structure, multiwall carbon nanotubes and PEDOT layer on the $I-V$ characteristic of the polymers. The differences found in the $I-V$ characteristic of the poly(azomethine)s confirm the difference planarity of the polymers structure and different conformations of the polymers in film. Our study shows that PEDOT used as interlayer between conductive ITO and polymer:MWCNT active layer caused increase of resistance of devices. On the other hand, multiwall carbon nanotubes influence on increase of conductivity of device (see Fig. 6a,b).

\section{Conclusion}

Spectroscopic and photophysical properties of three poly(azomethine)s bearing a triphenylamine moiety were investigated. The following conclusions can be drawn from the present work. Photoluminescence properties and optical band gap depend on the polymer structure. The photoluminescence properties in solid state exhibit all poly(azomethine)s and are observed in the range of 465-497 nm, depend on the diamine sub-unit. The band gaps $\left(E_{\mathrm{g}}\right)$ of the polymer films were calculated from the optical absorption edge and were observed at the range 2.33-2.44 eV depend on the polymer structure. Currentvoltage experiment confirmed the semiconducting properties of the polymer thin film. Multiwall carbon nanotubes added to polymer caused the increase of conductivity.

\section{Acknowledgments}

The authors thank Dr. eng. W. Mielcarek for X-ray measurements. This work was financially supported in the frame of expenditure on science (2010-2011) No. NN510191538.

\section{References}

[1] H. Shirakawa, Angew. Chem. Int. Ed. 40, 2574 (2001).

[2] A.G. MacDiarmid, Angew. Chem. Int. Ed. 40, 2581 (2001).

[3] A.J. Heeger, Angew. Chem. Int. Ed. 40, 2591 (2001).

[4] D. Sek, A. Iwan, B. Jarzabek, B. Kaczmarczyk, J. Kasperczyk, H. Janeczek, Z. Mazurak, Spectrochim. Acta Part A, Mol. Biomol. Spec. 72, 1 (2009).

[5] H. Niu, Y. Huang, X. Bai, X. Li, G. Zhang, Mater. Chem. Phys. 86, 33 (2004).

[6] H.-J. Niu, Y.-D. Huang, X.-D. Bai, X. Li, Mater. Lett. 58, 2979 (2004).

[7] D. Sek, A. Iwan, B. Kaczmarczyk, B. Jarzabek, J. Kasperczyk, H. Bednarski, High Perform. Polym. 19, 401 (2007).

[8] D. Sek, A. Iwan, B. Kaczmarczyk, B. Jarzabek, Mol. Cryst. Liq. Cryst. 468, 119 (2007). 
[9] D. Sek, A. Iwan, B. Jarzabek, B. Kaczmarczyk, J. Kasperczyk, Z. Mazurak, M. Domanski, K. Karon, M. Lapkowski, Macromolecules 41, 6653 (2008).

[10] D. Sek, A. Iwan, B. Jarzabek, B. Kaczmarczyk, J. Kasperczyk, H. Janeczek, Z. Mazurak, Spectrochim. Acta Part A, Mol. Biomol. Spectrosc. 72, 1 (2009).

[11] G.-S. Liou, H.-Y. Lin, Y.-L. Hsieh, Y.-L. Yang, J. Polym. Sci. Part A, Polym. Chem. 45, 4921 (2007).

[12] J.C. Hindson, B. Ulgut, R.H. Friend, N.C. Greenham, B. Norder, A. Kotlewski, T.J. Dingemans, J. Mater. Chem. 20, 937 (2010).

[13] G. Broza, K. Piszczek, K. Schulte, T. Sterzynski, Comp. Sci. Tech. 67, 890 (2007).

[14] E.T. Thostenson, Z. Ren, T.-W. Chou, Comp. Sci. Tech. 61, 1899 (2001).

[15] M. Moniruzzaman, K.I. Winey, Macromolecules 39, 5194 (2006)

[16] Ye. Mamunya, A. Boudenne, N. Lebovka, L. Ibos, Y. Candau, M. Lisunova, Comp. Sci. Tech. 68, 1981 (2008).

[17] M.O. Lisunova, Ye.P. Mamunya, N.I. Lebovka, A.V. Melezhyk, Europ. Polym. J. 43, 949 (2007).

[18] J.K.W. Sandler, J.E. Kirk, I.A. Kinloch, M.S.P. Shaffer, A.H. Windle, Polymer 44, 5893 (2003).
[19] E. Lafuente, M. Pinol, L. Oriol, E. Munoz, A.M. Benito, W.K. Maser, A.B. Dalton, J.L. Serrano, M.T. Martinez, Mater. Sci. Eng. C 26, 1198 (2006).

[20] G.D. Sharma, S.G. Sandogaker, M.S. Roy, Thin Solid Films 278, 129 (1996).

[21] T. Nakashima, N. Satoh, K. Albrecht, K. Yamamoto, Chem. Mater. 20, 2538 (2008).

[22] K. Yamamoto, K. Takanashi, Polymer 49, 4033 (2008).

[23] M.S. Weaver, D.D.C. Bradley, Synth. Met. 83, 61 (1996).

[24] T.E. Olinga, S. Destri, C. Botta, W. Porzio, R. Consonni, Macromolecules 31, 1070 (1998).

[25] S.C. Suh, S.C. Shim, Synth. Met. 114, 91 (2000).

[26] G.I. Rusu, A. Airinei, M. Rusu, P. Prepelit, L. Marin, V. Cozan, I.I. Rusu, Acta Mater. 55, 433 (2007).

[27] B. Jarzabek, J. Weszka, A. Burian, G. Pocztowski, Thin Solid Films 279, 204 (1996).

[28] B. Jarzabek, J. Weszka, M. Domanski, J. Jurusik, J. Cisowski, J. Non-Cryst. Sol. 354, 856 (2008). 